\title{
Formation Evaluation and Contingent Storage Capacity Estimation for Carbon Capture Storage and Utilization: A Case Study from East Natuna
}

\author{
Jeres R. Cherdasa ${ }^{1}$, Ken Prabowo ${ }^{1}$, Tutuka Ariadji ${ }^{1}$, Benyamin Sapiie ${ }^{1} \&$ Zuher Syihab $^{1}$ \\ ${ }^{1}$ Institut Teknologi Bandung, Indonesia \\ Correspondence: Jeres R. Cherdasa, Institut Teknologi Bandung, Indonesia. E-mail: jeresrorym@yahoo.com
}

Received: February 1, 2018

Accepted: February 13, 2018

Online Published: March 30, 2018

doi:10.5539/mas.v12n4p151

URL: https://doi.org/10.5539/mas.v12n4p151

\begin{abstract}
East Natuna is well known for its humongous natural gas reserves with a high $\mathrm{CO}_{2}$ content. The high quantity of carbon dioxide requires implementation cutting-edge capture and storage process in its development plan which comes at a high cost. In order to increase the economic feasibility of the area, the impurities are proposed to be utilized $\mathrm{CO} 2$ as working fluid further to generate electricity through Enhanced Geothermal System (EGS). Carbon dioxide has been proven to be a better fluid for EGS as it could reach super critical state in much lower pressure and temperature compared to brine water. Sokang Trough Area in East Natuna Basin was selected as a candidate for pilot project due to its favorable geological condition.

Carbon Capture Storage and Utilization (CCSU) especially EGS in sedimentary basin requires a suitable reservoir that fulfills several geological and engineering parameters. Firstly, it should porous enough to store fluid and permeable to flow it. The storage should also be deep enough to retain temperature above $87.98^{\circ} \mathrm{F}$ and pressure above $1071 \mathrm{psi}$ in order to keep the $\mathrm{CO}_{2}$ in supercritical phase. Even further, EGS requires a minimum reservoir temperature of $\pm 300^{\circ} \mathrm{F}$ to be technologically viable. In order to avoid vertical unintended migration, the reservoir should have high water saturation instead of gas saturation. Lastly, the seal should be able to confine the injected $\mathrm{CO}_{2}$ column within the storage.

Formation evaluation workflow adapted for CCSU was employed in this study. Porosity, water saturation and permeability was estimated through deterministic approach. Formation pressure was calculated using Eaton's equation. Reservoir temperature was estimated from available well testing data. Storage capacity was estimated for the whole structure with several cases. Considering all those parameters, several suitable reservoirs were able to be delineated in the CCS-1 well that is located within the East Natuna area.
\end{abstract}

Keywords: CCSU, formation evaluation, EGS, East Natuna, carbon dioxide

\section{Introduction}

The demand for natural gas in Indonesia keeps increasing as the population grows. In order to keep up with the needs, the oil and gas industry has to go back and re - evaluate untapped potential that has been sleeping for ages due to technical and economic reason. In the last few decades, one of the biggest discovery was made in East Natuna basin which is located in South China Sea (Figure 1). The resources in the area were estimated to be around 222 TCF with $70 \%$ of it is carbon dioxide (Dunn, et.al., 1996), which leaves \pm 40 TCF of methane to be extracted. However, the development of the gas prospects was inconceivable due to the high content of carbon dioxide which is highly corrosive, requires cutting edge separation technology and also has to be safely disposed without releasing it into the atmosphere.

Carbon Capture and Storage (CCS) where the captured $\mathrm{CO} 2$ is safely stored in subsurface reservoir has significantly improved to the point where it has become economically feasible. The world's first CCS operation, Sleipner CCS project was even done in the North Sea, offshore area of Norway. A new scheme called Carbon Capture, Storage and Utilization (CCSU) was proposed in order to increases the economic feasibility of the operation that might enable the development of gas resource in East Natuna. Carbon dioxide which has relatively low critical point was proposed to be utilized as heat transmission fluid for Enhanced Geothermal System (EGS) (Pruess \& Spycher, 2010) which in turn could be used to generate electricity for the whole region (Figure 2). Evaluation whether CCSU could be implemented starts with identification of suitable deep saline aquifer below 
that could be utilized as storage for the greenhouse gas. Within East Natuna Basin where the sleeping Giant Gas Field exist with problematics high $\mathrm{CO} 2$ content the last research within this area is conducting the investigation of storage efficiency for $\mathrm{CO} 2$ in water-saturated Carbonate Aquifers by having a laboratory experiment evaluation for the solubility of $\mathrm{CO} 2$ in water at various temperatures within several core plugs (Sugihardjo et.al.,1999). This Paper is meant to elaborate the CSSU workflow that has been done to evaluate the presence of Sandstone unit aquifer in Arang Formation as one of the reservoir object for CO2 CCSU project therefore the Sleeping Giant Gas field could be produced within safely environmental and economical condition.

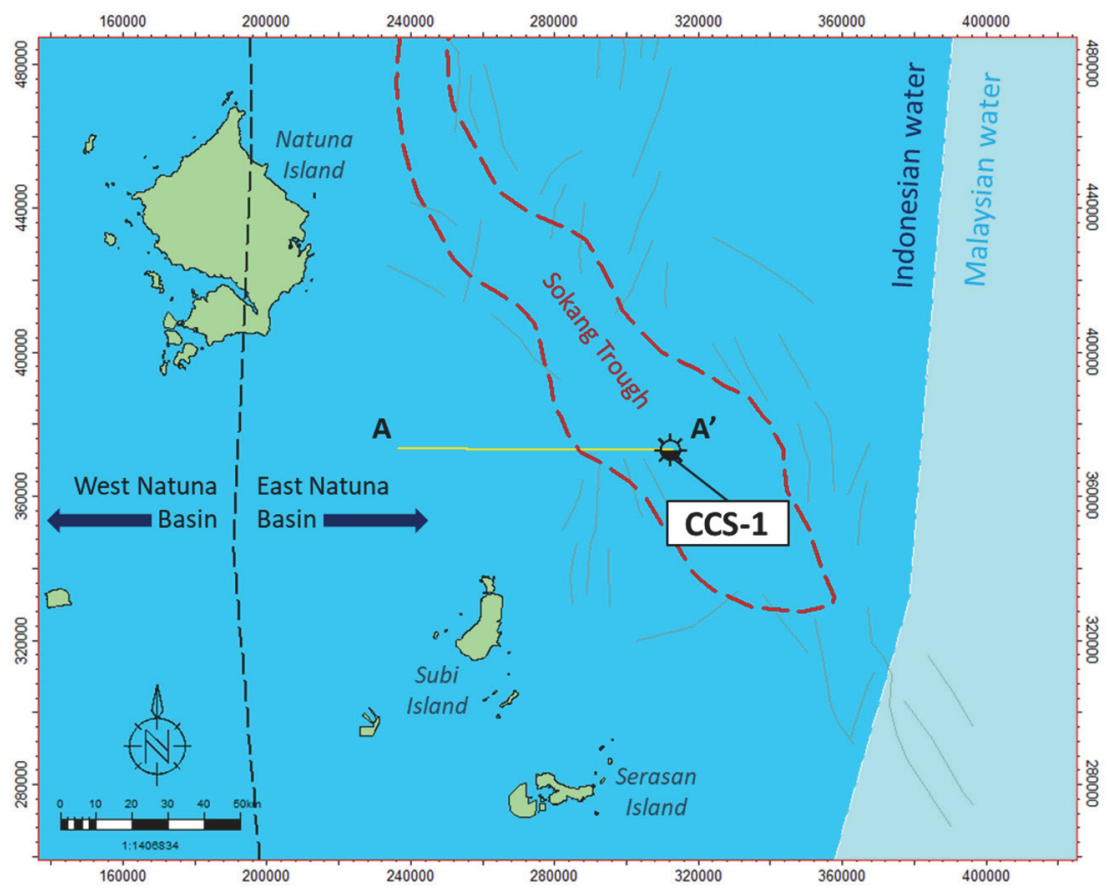

Figure 1. Location of the CCS-1 well in the South China Sea

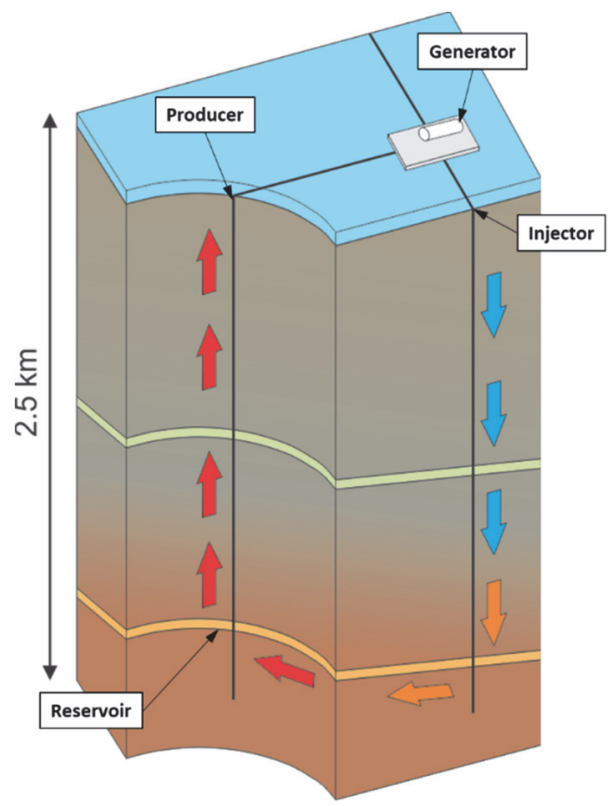

Figure 2. Utilization of the carbon dioxide in an Enhanced Geothermal System

\section{Methodology}

The CSSU method with an EGS operation circulates fluid thousand feet beneath the surface to extract heat generated by the geothermal gradient. In order to do that, it requires: 
1. a reservoir with adequate porosity and permeability to flow gas $(\mathrm{k}>1 \mathrm{md})$,

2. located within an area with high geothermal gradient $\left(\mathrm{T}_{\text {grad }}=37 \pm 10^{\circ} \mathrm{F} / 1000 \mathrm{ft}\right)$,

3. formation pressure and temperature has to be high enough to keep the carbon dioxide in super critical condition $\left(\mathrm{T}>87.98^{\circ} \mathrm{F}\right.$ and $\left.\mathrm{P}>1071 \mathrm{psi}\right)$,

4. impermeable seal to prevent leakage of the fluid agent $(\mathrm{k}<1 \mathrm{md})$ and

5. a trap to direct the fluid flow injector from producer well.

The CCS-1 well was a wild cat with a total depth of $7740 \mathrm{ft}(2359 \mathrm{~m})$. The target was a four-way dipping anticline that was discovered through subsurface imaging using seismic data where it is penetrated the Muda Formation and Upper Arang Formation (Figure 3).

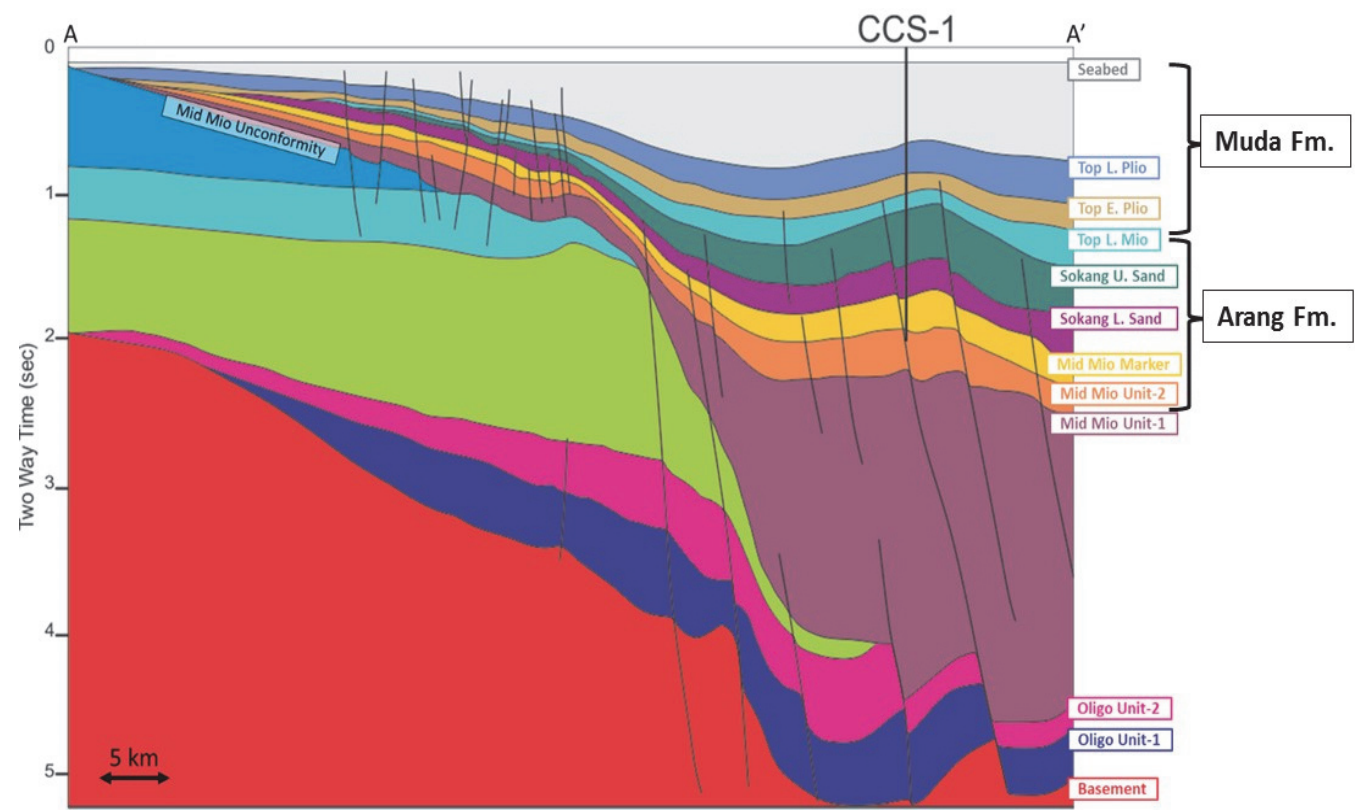

Figure 3. Cross section of the CCS-1 well and its target structure redrawn from (Raharja, Carmody, Cherdasa, \& Haribowo, 2013)

Figure 4 shows the regional stratigraphy of East Natuna Basin. The shale prone Muda Formation acts as regional seal while the reservoir could be found in Upper Arang Formation or Sokang Sandstone unit. Thus it leaves the identification of the reservoir and seal that fulfilled the aforementioned criteria.

Formation evaluation is the process of evaluating a geological formation through petrophysical characterization. The oil and gas industry has been using wireline logs that was acquired while drilling the formation to find out whether the wellbore penetrated any hydrocarbon bearing reservoir or pay zone.

The available data and workflow for this study is shown in Figure 5. Formation evaluation was conducted to systematically identify the most suitable reservoir for an EGS. Subsurface temperature was analyzed based on the available temperature logging that was done during production test and open hole logging. Lithology was determined through gamma ray (GR), neutron porosity (NPHI), density (RHOB) and mud log altogether. Clay volume was calculated afterward using GR based on the linear relationship. Total and effective porosity was calculated using the density neutron model. Water saturation was calculated using the Indonesian equation due to the shaly sandstone characteristic that is usually encountered in shallow marine deposit. Lastly, the pore pressure was quantified based on sonic log using the Eaton's equation. Cut - off for the reservoir would be derived from the clay volume, effective porosity, water saturation, formation pressure and temperature. 


\section{WEST NATUNA}

\section{EAST NATUNA}

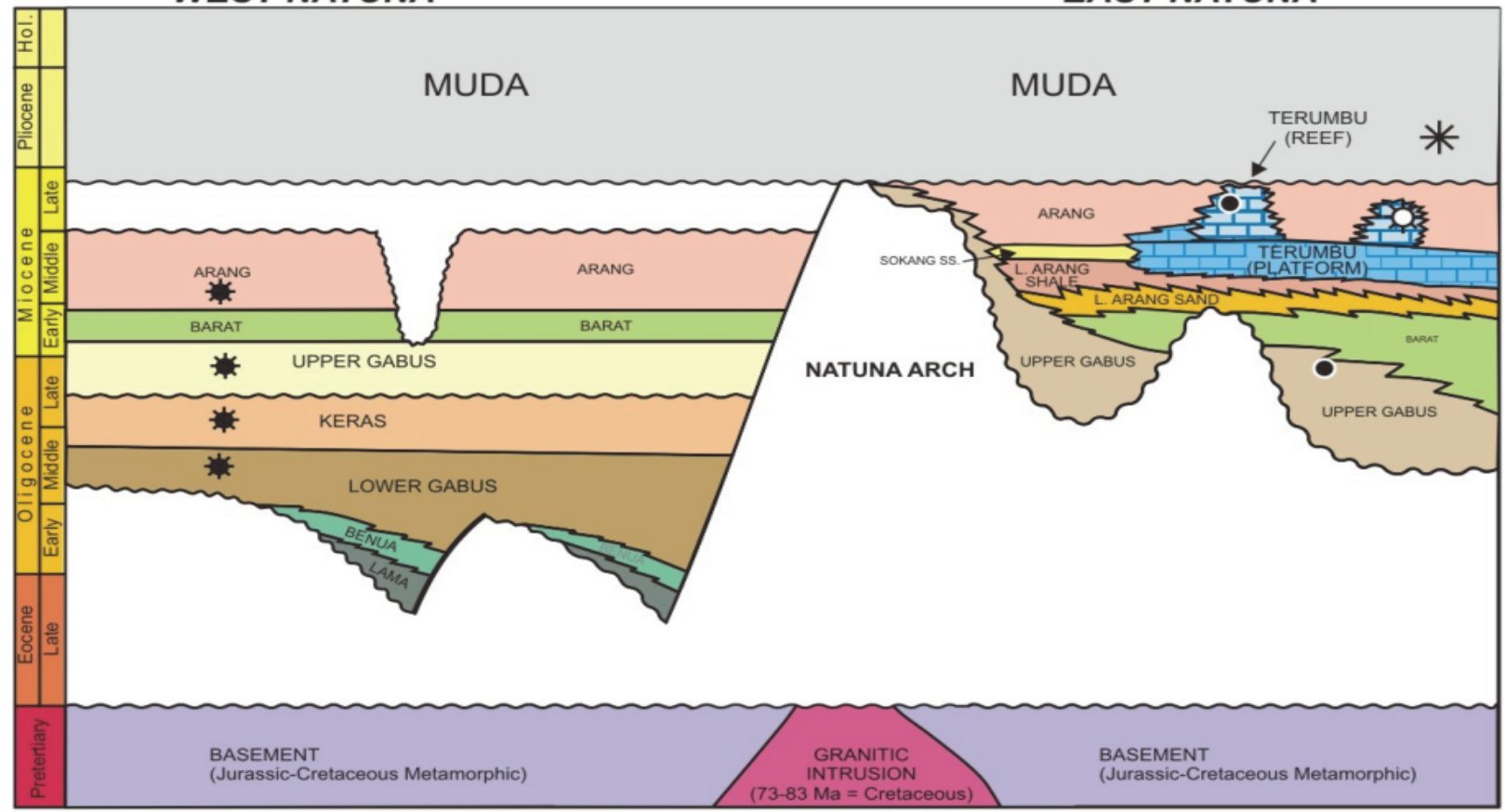

Figure 4. Regional stratigraphy of East Natuna Basin (Darman, 2017)

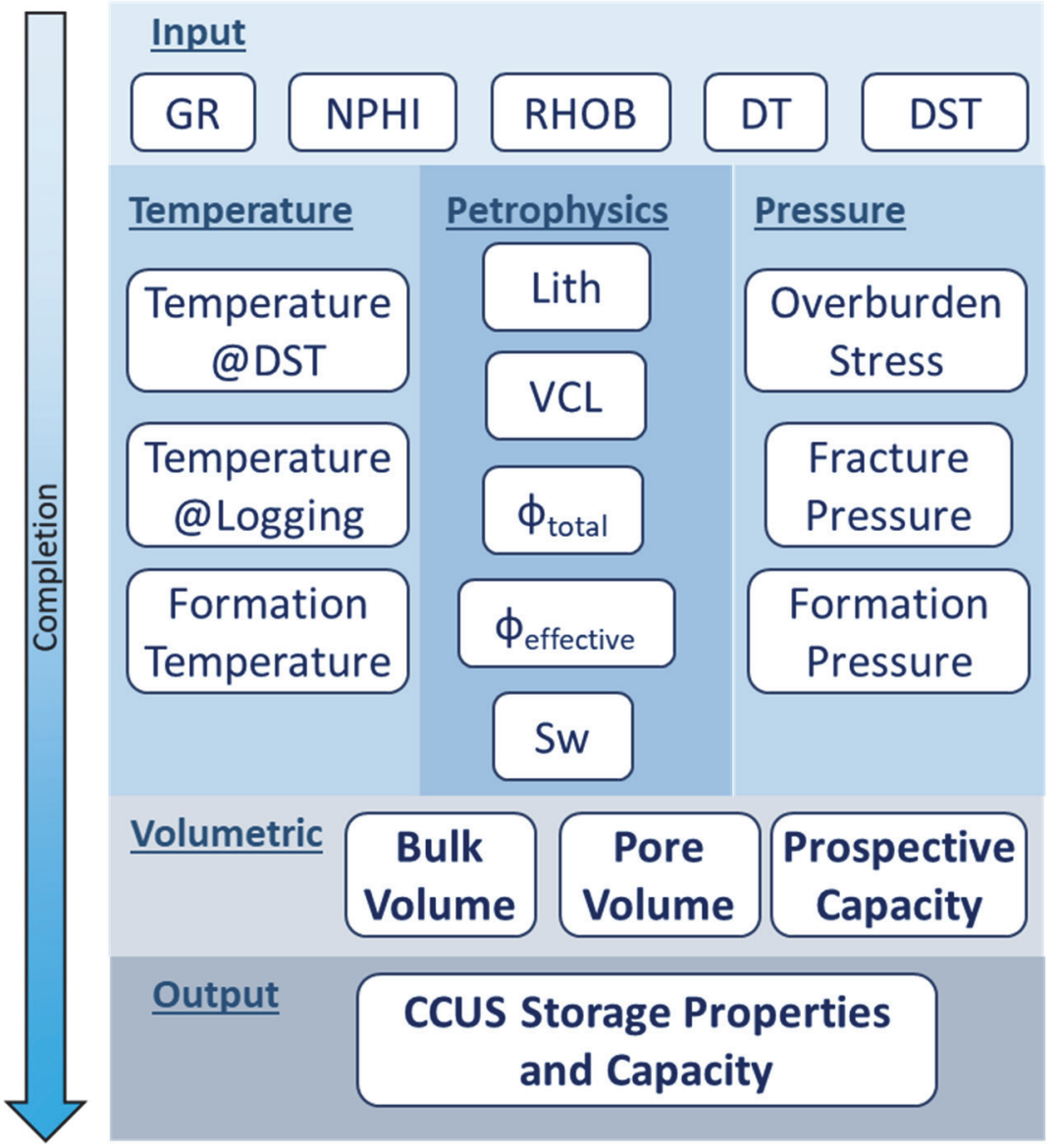

Figure 5. Formation evaluation workflow for identifying suitable CCSU reservoir 
Clay volume is the fraction of clay within the formation. There are several methods to calculate that include linear as well as several non-linear methods. All non-linear relationships have to be calibrated with calculated clay volume from core data because it resulted in more optimistic or smaller clay volume. Thus, the linear equation shown below (Equation 1) was used due to the minimum availability of the data (Holstein, 2007).

$$
V_{\text {Clay }}=\frac{G R_{\text {log }}-G R_{\min }}{G R_{\max }-G R_{\min }}
$$

Total porosity that means the total void space per rock volume and effective porosity is the interconnected pore volume or void space in a rock that contributes to fluid flow or permeability in a reservoir. Density porosity is calculated using Equation 2 which is used further to calculate neutron - density porosity as shown in Equation 3 (Buryakovsky, Chilingar, Rieke, \& Shin, 2012).

$$
\begin{gathered}
\phi_{D}=\frac{\left(\rho_{m a}-\rho_{b}\right)}{\left(\rho_{m a}-\rho_{f l}\right)} \ldots . . \\
\phi_{\text {total }}=\sqrt{\frac{\phi_{D}^{2}+\phi_{N}^{2}}{2}} .
\end{gathered}
$$

Effective porosity excludes isolated pores and pore volume occupied by water adsorbed on clay minerals or other grains. The simple petrophysical model subtract total porosity with clay bound water as shown in Equation 4 (Holstein, 2007).

$$
\phi_{\text {eff }}=\phi_{\text {total }}-S_{w b}
$$

Water saturation is the fraction of water that filled the pore space. Indonesian model that is shown in Equation 5 (Holstein, 2007) was developed empirically from Indonesian field data in water bearing shaly sand. However, the equation could still be well applied to hydrocarbon bearing reservoir anywhere. It is often used when field specific special core analysis is unavailable.

$$
S_{w}=\left\{\left[\left(\frac{V_{s h}^{2-V_{s h}}}{R_{s h}}\right)^{1 / 2}+\left(\frac{\phi_{e}^{m}}{R_{w}}\right)^{1 / 2}\right]^{2} R_{t}\right\}^{-1 / n}
$$

Overburden $(\sigma)$ stress is the stress given by the weight of overlying geologic formations. It is formulated in Equation 6 (Zoback, 2007). The average gradient of the overburden stress is around $1 \mathrm{psi} / \mathrm{ft}$.

$$
\sigma(z)=p_{0}+g \int_{0}^{z} \rho(z) d z
$$

Effective stress $\left(\sigma^{\prime}\right)$ is the external load generated by contacts between the grains that makes up the difference between pore pressure and overburden stress. It could be written as shown in Equation 7 (Zoback, 2007).

$$
\sigma^{\prime}=\sigma-\alpha P_{p}
$$

Pore pressure $(\mathrm{Pp})$ is the pressure generated by fluid that fills the pore space in between the grains. Eaton transformed Equation 7 to Equation 8 in order to calculate the pore pressure using sonic log that is sensitive compaction (Mouchet \& Mitchell, 1989).

$$
P_{p}=\sigma-\left(\sigma-P_{h y d}\right)\left(\frac{\Delta T_{n}}{\Delta T_{l o g}}\right)^{3}
$$

Storage Capacity is calculated through volumetric method as shown in Equation 9 (Bachu, 2015). Bulk volume is multiplied from area and height using the depth structure map of top and base of the delineated storage. The lowest reservoir boundary of the area is using the spill point from the current depth structure Map. Pore volume is the bulk volume multiplied by effective porosity and net to gross ratio. Gas saturation is derived by subtracting 1 with water saturation. The lowest water saturation computed in within a formation that has similar characteristic in the CCS-1 well is assumed to be the residual water saturation. Thus, the pore volume is multiplied by maximum gas saturation to estimate the storage capacity.

$$
M_{C O 2}=C_{c} \iiint \phi_{e f f}\left(1-S w_{i r r}\right) \rho_{C O 2} d x d y d z
$$


Gas bearing reservoir proven by DST in the CCS-1 well and overlying shale unit is also used as an analogue for the storage and seal. The lowest water saturation calculation from gas bearing reservoir was assumed to be the maximum gas capacity that could be injected into the storage. The property of shale unit above the gas reservoir is also considered to be adequate as a seal as it could hold a reservoir with $87 \% \mathrm{CO}_{2}$ gas content.

\section{Result and Discussion}

\subsection{Formation Temperature}

The available temperature data in CCS-1 well is temperature recording from production test and from the open hole logging. Both data are shown in

Table 1 and plotted in Figure 6. The measurement from open hole logging was much lower compared to the one from DST. The comparatively low value from the logging might be due to introduction of the colder drilling mud into the well bore. Thus, geothermal gradient of $50.5^{\circ} \mathrm{F} / 1000 \mathrm{ft}$ (or $81^{\circ} \mathrm{C} / \mathrm{KM}$ ) that was derived from the DST was used for further analysis.

Table 1. Available temperature data in CCS-1 well

\begin{tabular}{|r|r|r|l|r|r|r|l|}
\hline No. & Depth (ft) & Temp (F) & Data & No. & Depth (ft) & Temp (F) & Data \\
\hline 1 & 1370 & 120.002 & Logger & 1 & 3273 & 189 & DST 7 \\
\hline 2 & 4314 & 165.992 & Logger & 2 & 4733 & 249 & DST 5 \\
\hline 3 & 6268 & 192.002 & Logger & 3 & 4883 & 251 & DST 4 \\
\hline 4 & 6852 & 194 & Logger & 4 & 5047 & 256 & DST 3 \\
\hline 5 & 7160 & 233.996 & Logger & 5 & 5250 & 265 & DST 2 \\
\hline 6 & 7737 & 240.008 & Logger & \multicolumn{4}{|l}{} \\
\hline
\end{tabular}

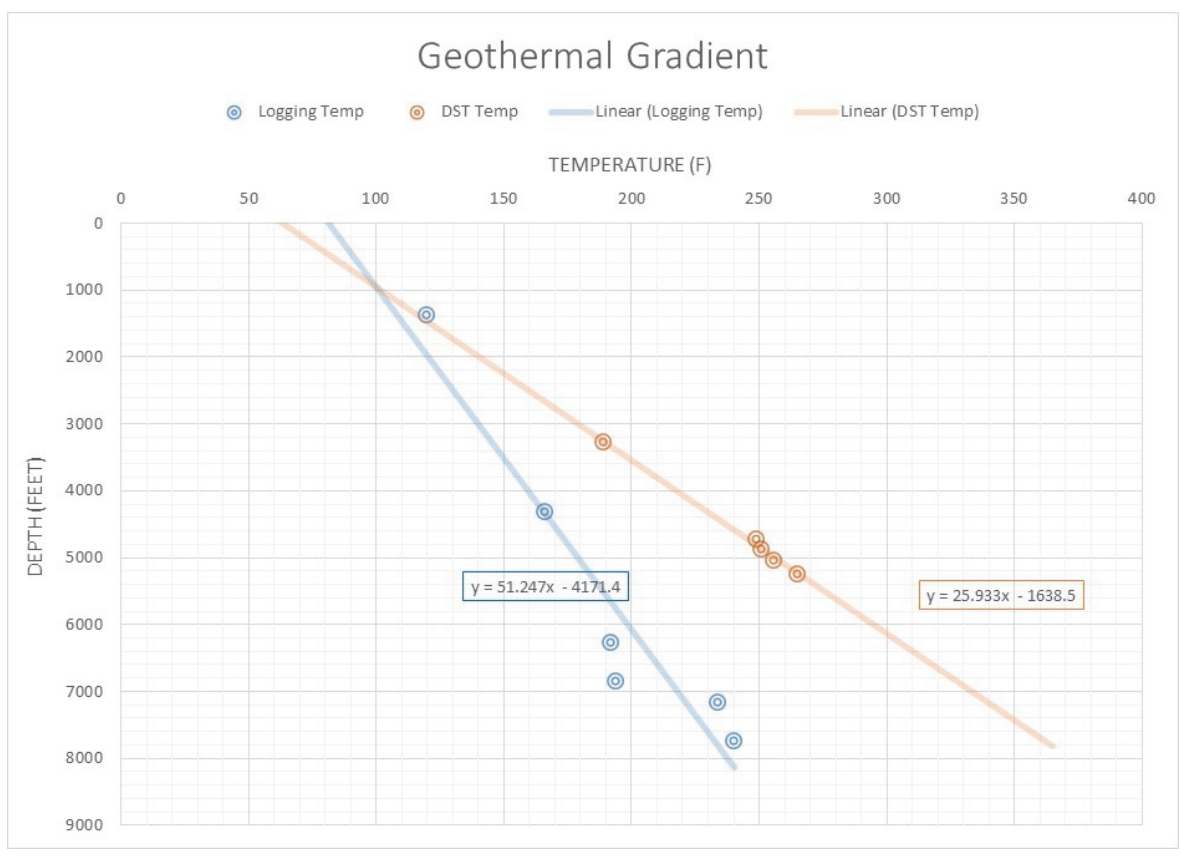

Figure 6. Temperature analysis of CCS -1 well

Geothermal gradient plot (Figure 7) from the Geothermal Research Council shows the use of thermal energy and required power plant. Above $20^{\circ} \mathrm{C}\left(68^{\circ} \mathrm{F}\right)$, geothermal waters could be used directly by human for greenhouses, aquaculture or district heating. Above $75^{\circ} \mathrm{C}\left(167^{\circ} \mathrm{F}\right)$, the fluid is hot enough to be used to generate electricity using the binary cycle technology. And beyond $160^{\circ} \mathrm{C}\left(320^{\circ} \mathrm{F}\right)$, flash steam generation can be used to generate electricity through flash steam power plant, the most common type of geothermal power plant. The geothermal gradient of CCS-1 was plotted into the geothermal resource plot and it shows that the area has a higher gradient compared to average EGS location and even on the borderline of conventional hydrothermal electricity generation. Therefore, the area has the potential to be utilized for an EGS operation. (GRC, 2017). 


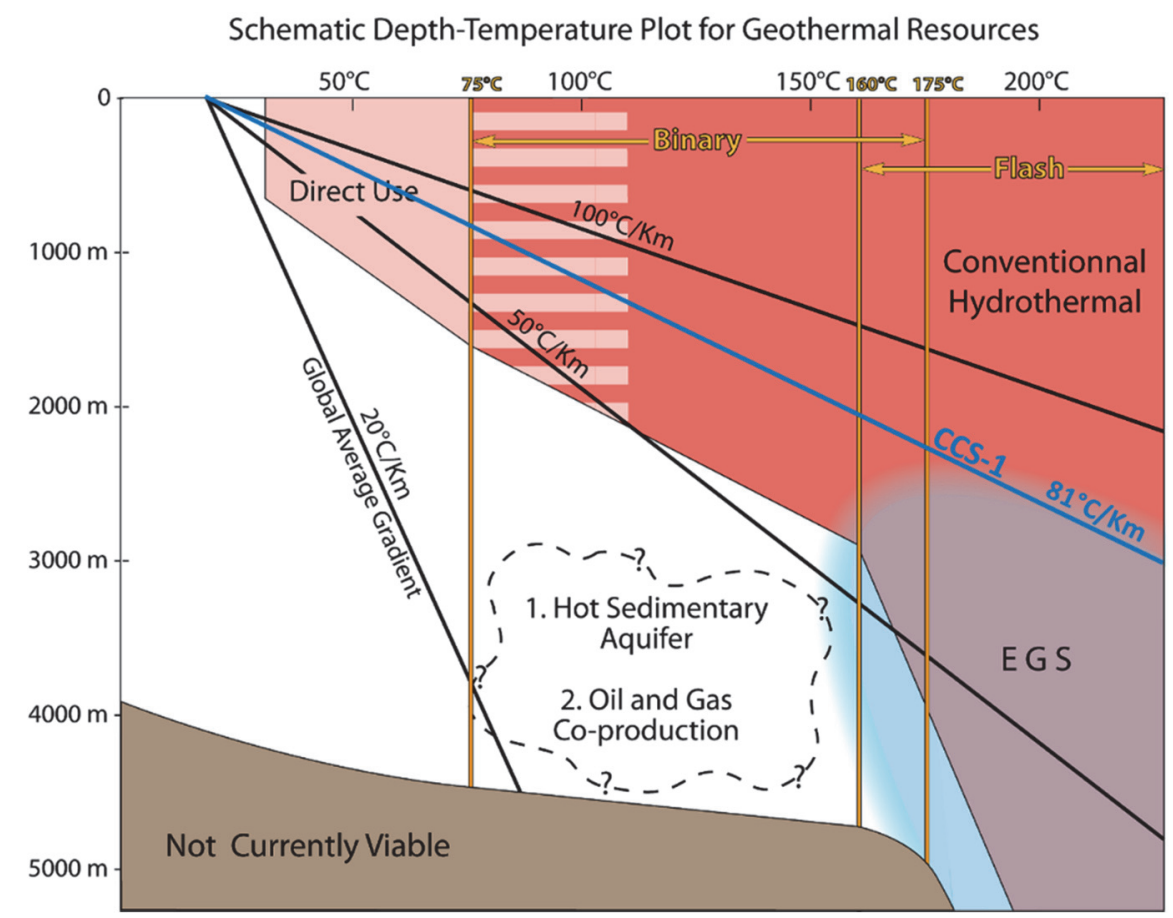

Figure 7. Depth - temperature geothermal resources plot that shows potential usage of CCS-1 well. (Modified from (GRC, 2017))

\subsection{Rock Typing}

Rock typing was done in order to get a better understanding regarding the reservoir character from the actual core sample that was taken from the drilling operation. The routine core analysis that measured porosity and permeability was done on 12 samples (Figure 8).

Hydraulic flow unit plot (Figure 9) is a plot between Reservoir Quality Index (RQI) and the normalized porosity index (Фz). The Reservoir Quality Index (RQI) is the parameter defined to characterize the rock quality based on the relation between permeability and porosity shown by equation 10 below (Benzagouta, 2013, Amaefule et.al,1993):

$$
\mathrm{RQI}=0.0314 \sqrt{\frac{k}{\phi_{e}}} .
$$

And the normalized porosity index $(\Phi z)$ is a pore volume to grain volume ratio which defined from equation 11 below (Benzagouta, 2013, Amaefule et.al,1993):

$$
\phi_{Z}=\frac{\Phi \mathrm{e}}{(1-\Phi \mathrm{e})} .
$$

From the plot shows that the samples could be classified into three rock types with the following parameters. RT-1 has the best quality as a reservoir and on the other end of the spectrum, RT -3 has the worst quality as a reservoir. RT-3 would later be used to determine cut-off for the CCSU storage.

Table 2 shows the flow zone indicator (FZI), average porosity and permeability of each rock type. The Flow Zone Indicator (FZI) is derived from Rock Quality Index and normalized porosity index $(\Phi \mathrm{z})$ which shown by equation 12 below (Benzagouta, 2013, Amaefule et.al,1993):

$$
F Z I=\frac{\mathrm{RQI}}{\Phi \mathrm{Z}}
$$




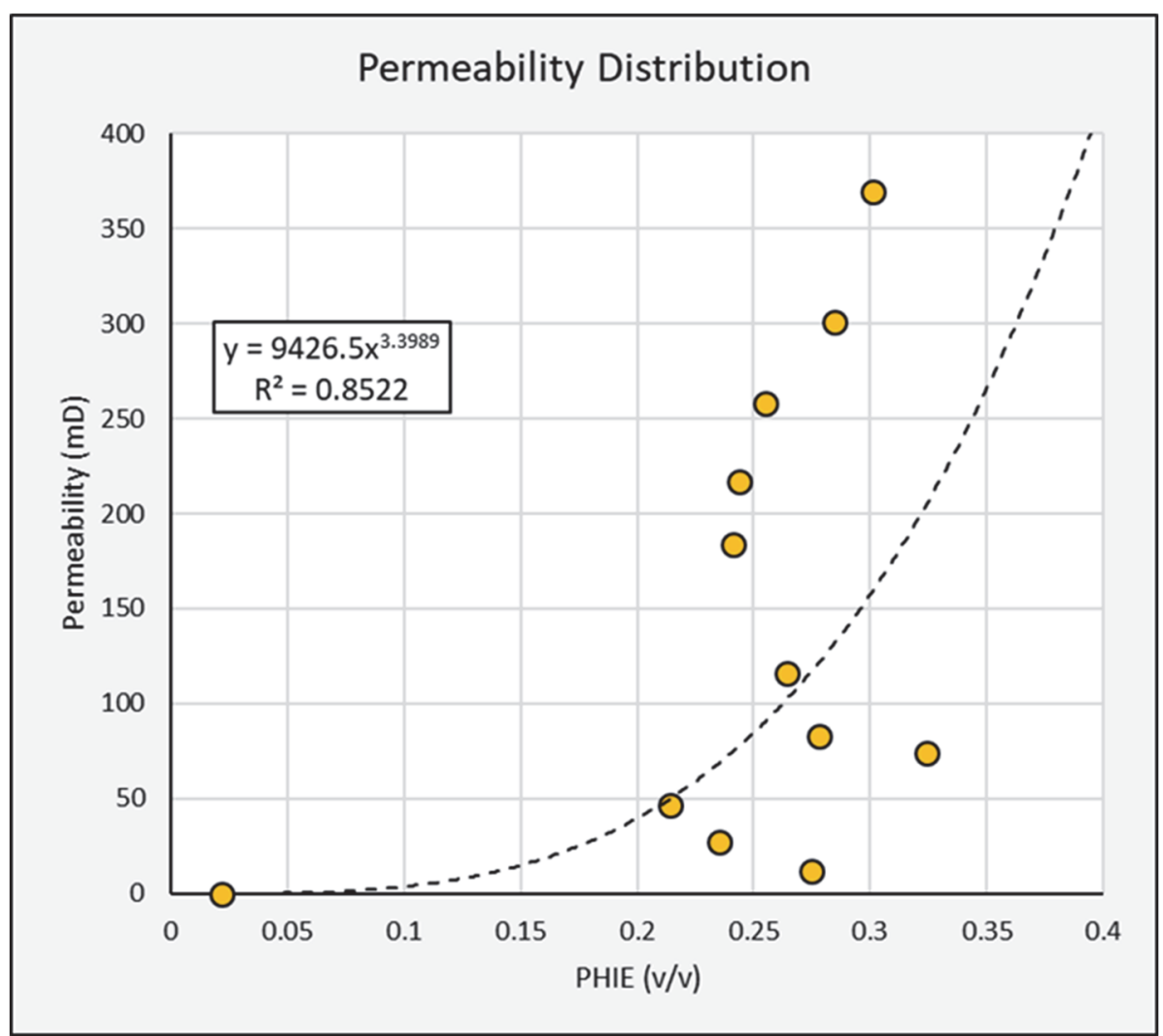

Figure 8. Porosity - permeability distribution of CCS-1 core sample.

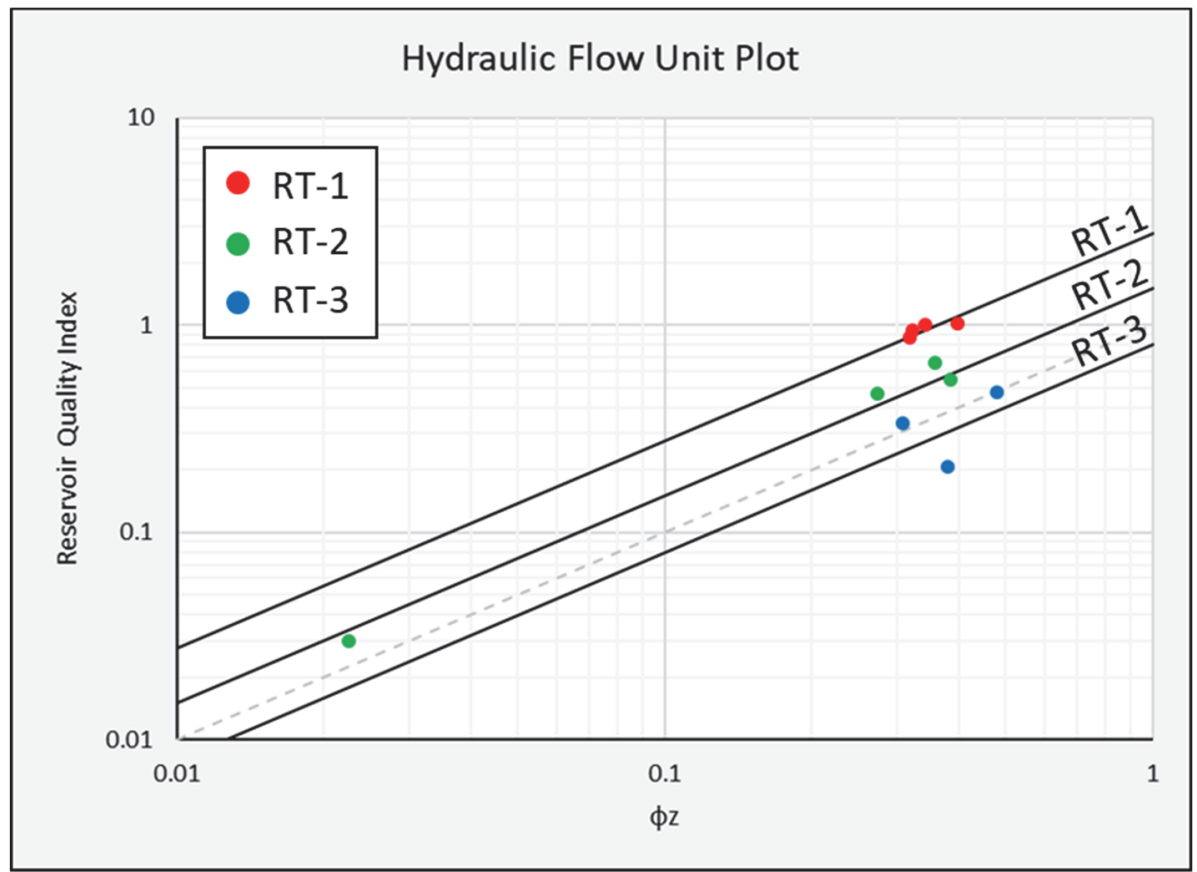

Figure 9. RQI - pz plot for hydraulic flow unit classification

Table 2. Hydraulic flow unit summary of rock types in CCS-1 well

\begin{tabular}{|c|c|c|}
\hline \multicolumn{3}{|c|}{ RT FZI k Average $(\mathrm{mD}) \phi$ Average $(\mathrm{v} / \mathrm{v})$} \\
\hline 1 & 2.75265 .8 & 0.2652 \\
\hline 2 & $1.5 \quad 61.5$ & 0.1945 \\
\hline 3 & $0.8 \quad 37.7$ & 0.278 \\
\hline
\end{tabular}




\subsection{Petrophysical Analysis}

The formation was evaluated using linear clay volume equation, density neutron porosity equation and Indonesian water saturation equation. In the linear clay volume calculation, the minimum and maximum ratio of the GR was adjusted per formation.

Figure 10-A figure is showing the cross plot between Porosity and Density for each lithology at CCS-1 well, the lithology cluster is being divided into 5 units which is Blue Unit is the Storage unit interval, Yellow is the Reservoir unit or sandstone dominated, Red Unit is the Reservoir section being tested by DST's, Green Unit is for Shale Interval and Dark Green Unit is for Seal interval above the Storage Section. From the plot it could be seen the Shale and Seal section is filling the Upper Right Zone Area (High NPHI and Medium - Low RHOB values) where showing the Shale Effect zone is. For Reservoir Tested Interval unit is located at the Upper Left Zone Area (Medium - Low NPHI and Medium - Low RHOB values) where showing the Gas Effect zone is, and this is match with the DST's results from the CCS-1 well. The Reservoir and Storage Unit is located at the Lower and Middle Zone which have a Medium - Lower NPHI and Medium - High RHOB.

Figure 10-B figure is showing the picket plot between resistivity and porosity for water saturation (Sw) calculation result with parameters such as water resistivity $(\mathrm{Rw})=0.108$, cementation constant $(\mathrm{a})=1$, cementation exponent $(\mathrm{m})=2$, tortuosity factor $(\mathrm{n})=2$. The Tested interval showing by the red unit is having a Sw value between $0.3-0.6$ and the shale and seal interval showing by the green and dark green unit mainly is below the red line or below the $\mathrm{Sw}=0.7$. While the Storage interval showing in blue unit is having a $\mathrm{Sw}$ value ranging in 0.7 value and the reservoir showing in yellow unit mainly clustered in Sw value below 0.7.

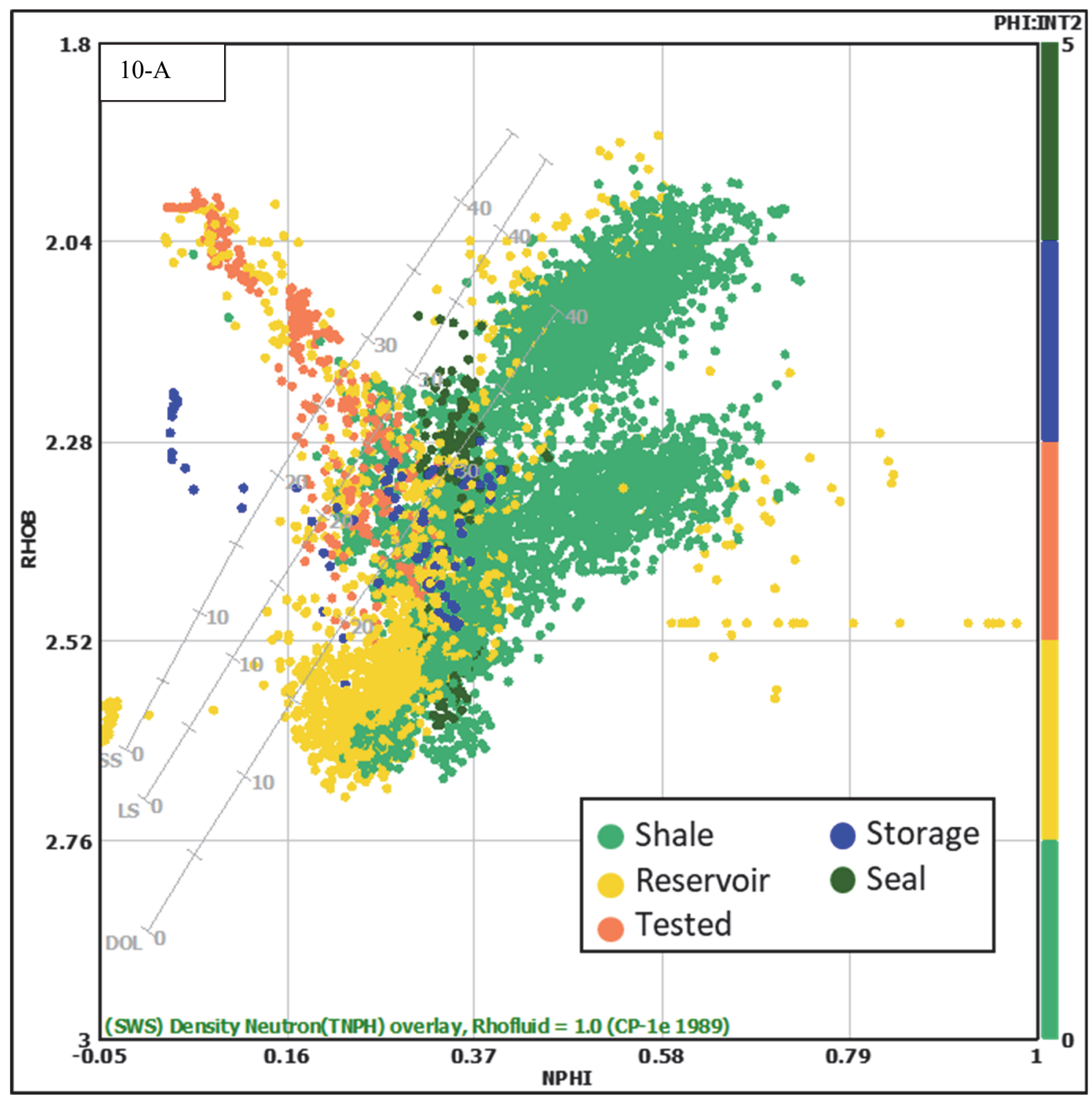




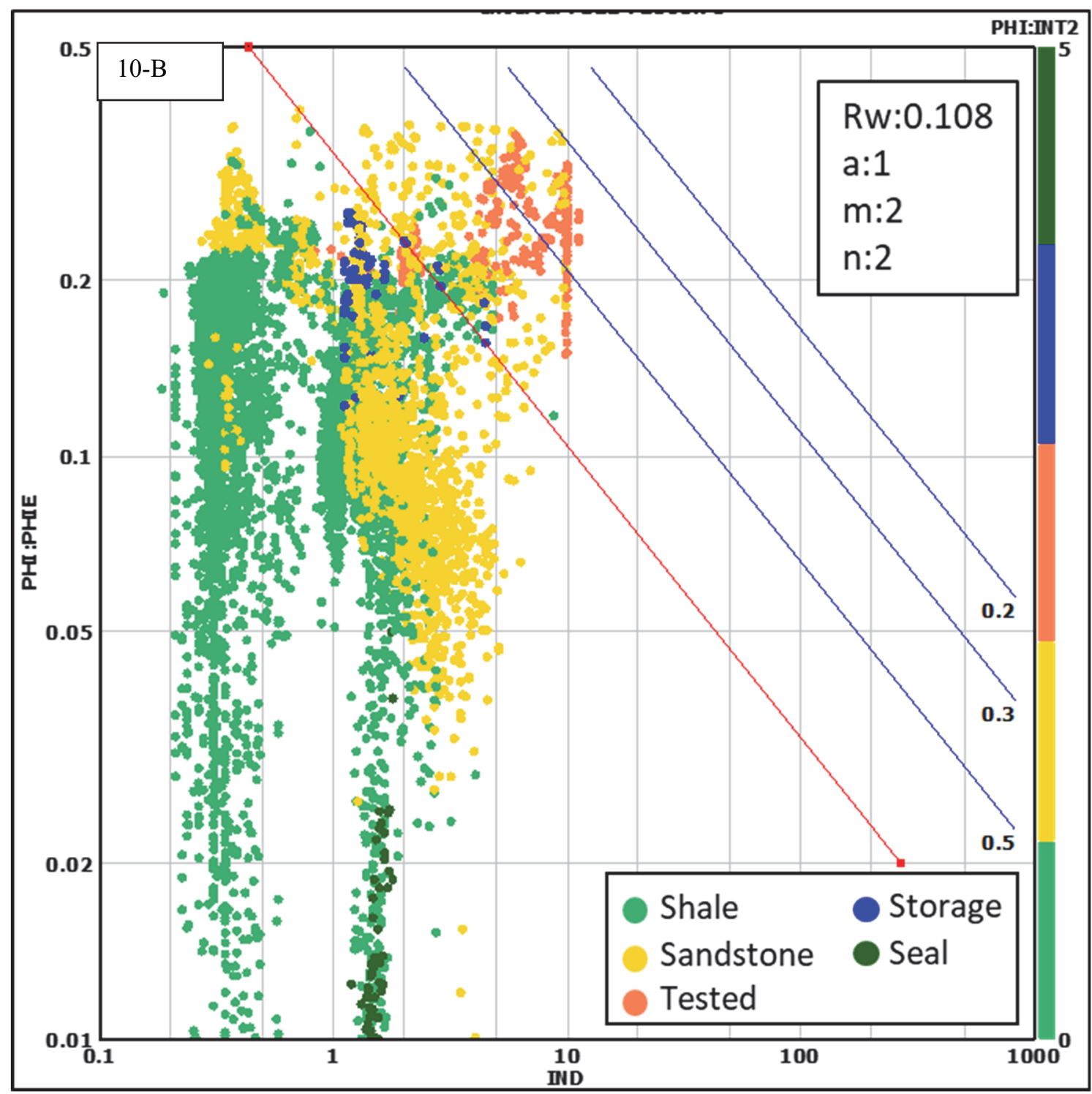

Figure 10. Petrophysical calculation parameters for density neutron porosity (Fig. 10-A) and picket plot for water saturation (Fig. 10-B)

The reservoir characterization result is for each formation is discussed below.

\section{Muda Formation}

The Muda Formation was found underneath the seabed all the way to the depth of $3214 \mathrm{ft}$ (Figure 11). The dominant lithology is shale followed by a few intercalations of siltstone and limestone. The formation serves as the regional seal within the East Natuna Basin. There is no sign of hydrocarbon bearing reservoir within logged interval. For a CCSU operation, the formation could serve as secondary seal. 


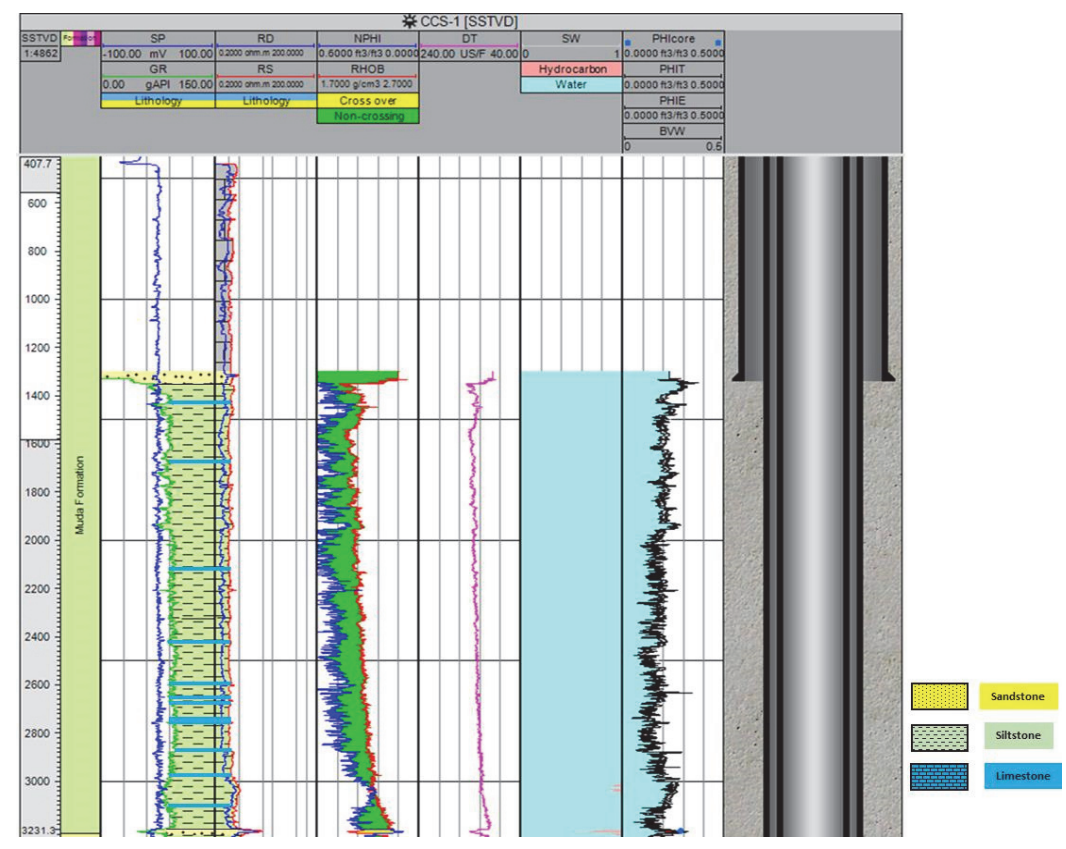

Figure 11. Petrophysical calculation result of Muda Formation

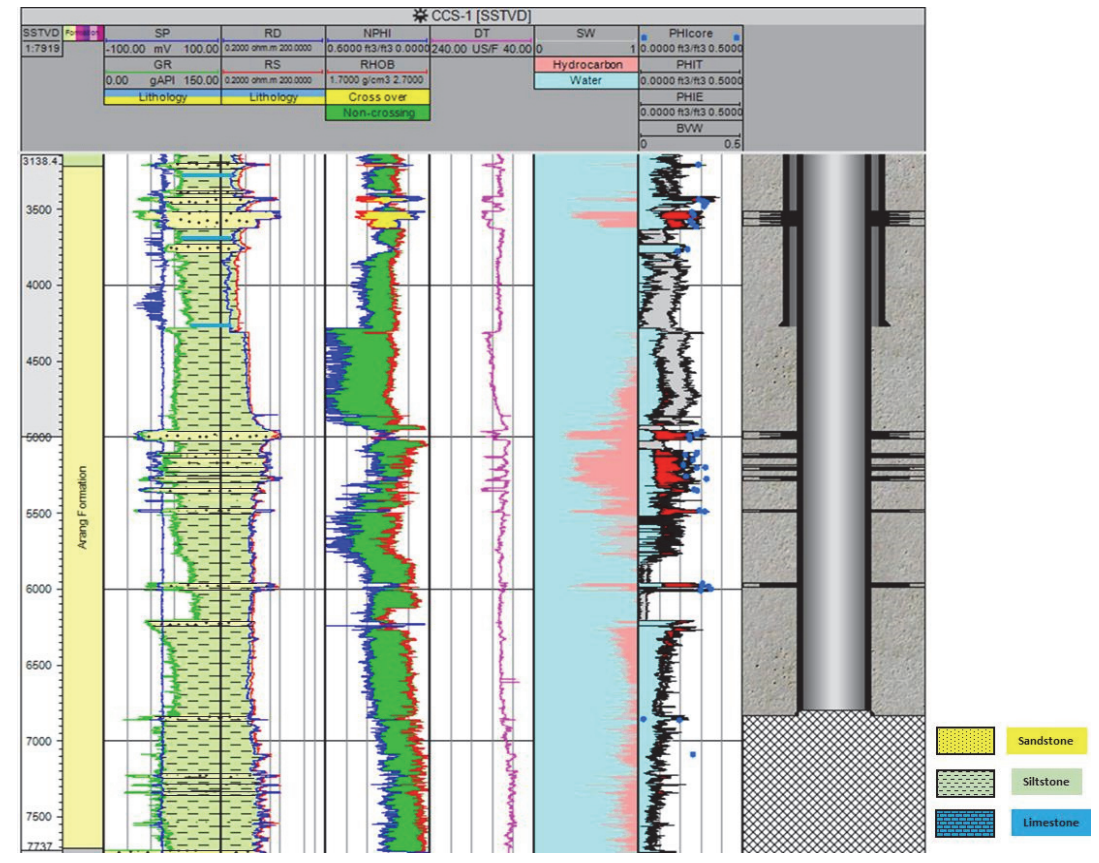

Figure 12. Petrophysical calculation result of Arang Formation

\section{$\underline{\text { Arang Formation }}$}

The Arang Formation was found at the depth of $3214 \mathrm{ft}$ to TD (Figure 12). The dominant lithology is shale followed by a few intercalations of sandstone and siltstone. Several hydrocarbon bearing interval was found within the formation. Seven production test has been conducted with 6 confirmed production of gas. The storage candidate for CCSU storage could be found in this formation as there are several proven permeable sandstones. The claystone would serve as an intra-formational seal.

\subsection{Formation Pressure}

Pore pressure calculation that has been validated with initial pressure is shown in Figure 13. The pressure to the depth of $5500 \mathrm{ft}$ shows normal hydrostatic gradient with fluctuation at the gas bearing sandstones. Below the depth of $5500 \mathrm{ft}$, overpressure start to occur with a gradient as high as $0.73 \mathrm{psi} / \mathrm{ft}$ at the total depth. 


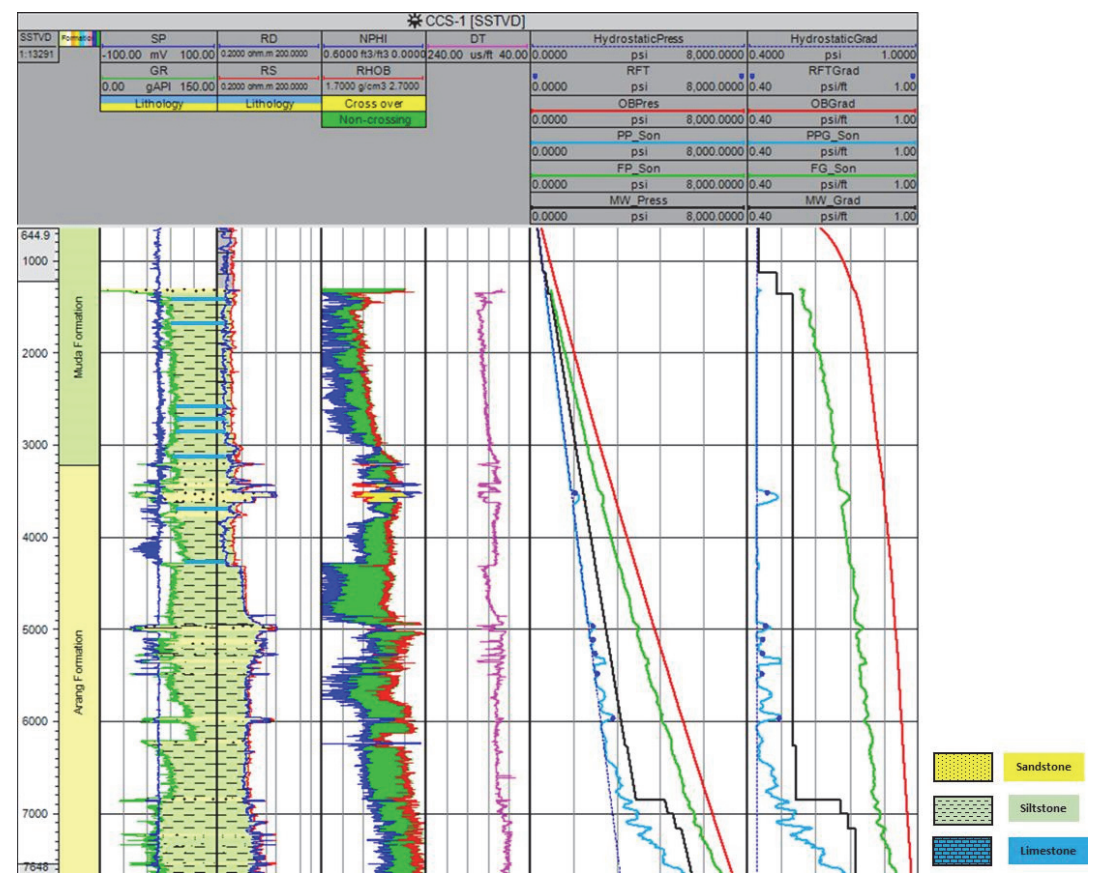

Figure 13. Pore pressure calculation result validated with measured pressure from DST

\subsection{Cut-off Determination}

The cut off for the CCSU storage and seal started in the poro - perm plot (Figure 14). A minimum permeability of $1 \mathrm{mD}$ is assumed to be able to flow gas through the pore throats of the reservoir (Baker, Yarranton, \& Jensen, 2015). The RT-3, lowest reservoir quality is used to determine cut - off for the effective porosity. The result shows that $1 \mathrm{mD}$ in $\mathrm{RT}-3$ is equal to 0.1071 of effective porosity in RT -3 . Therefore, the value of 0.1071 would be used for further reservoir delineation.

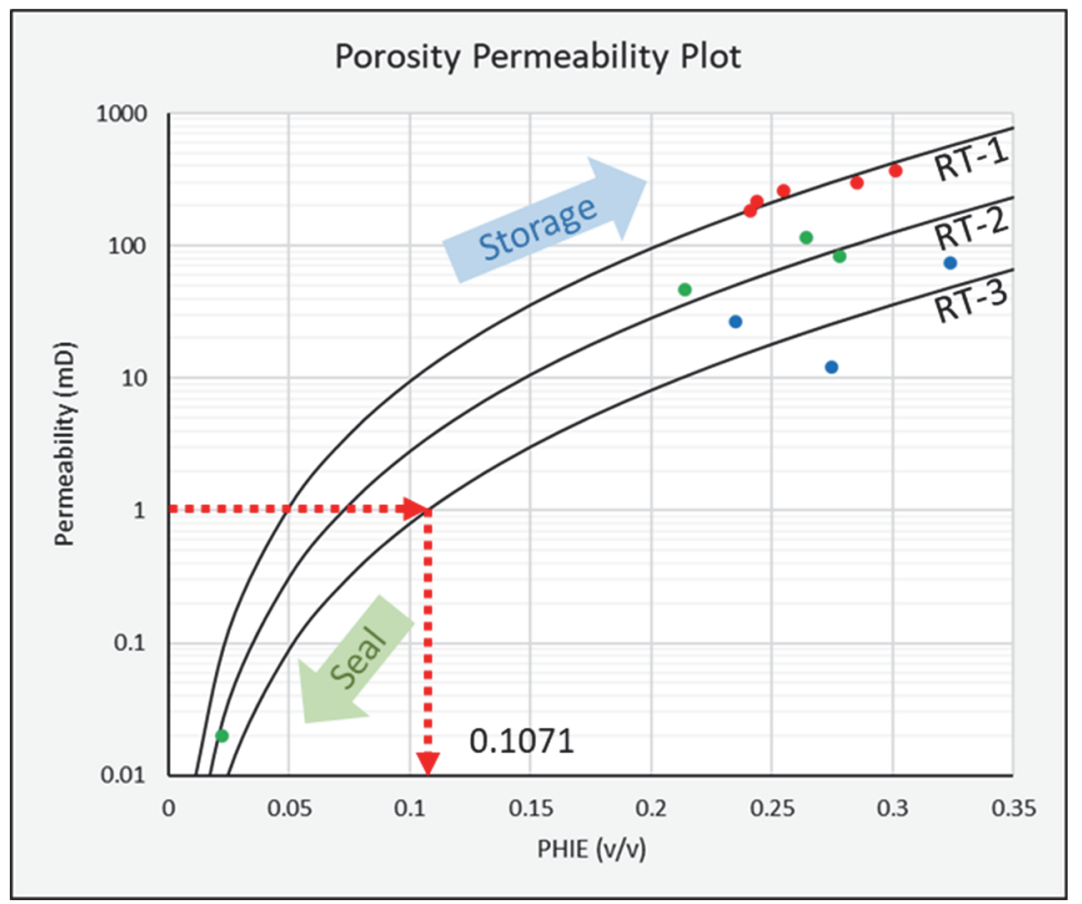

Figure 14. Porosity permeability plot overlain with hydraulic flow unit curves for effective porosity determination cut off 
Separation of reservoir with shale or tight sandstone requires the plotting of effective porosity versus clay volume as shown in Figure 15. The Cut - off value for clay volume was determined by distinguishing the tested interval (DST's) in the wellbore that has been proven to flow gas. The highest clay volume in the tested reservoir is 0.5. Combining with the cut off for effective porosity, we have identified the area where potential storage lies. Bottom right corner of the graph shows where the potential storage is while the upper left corner shows where potential seal is (Figure 15-A).

Lastly, ideal reservoir for a CCSU operation required an interval with high water saturation. Addition of carbon dioxide into gas bearing reservoir is more likely to frack the seal above. Determination of the pay zone was also done by identifying tested intervals as shown in 错误!未找到引用源。 Based on the plot, the lowest porous interval as a water saturation of 0.67 . Thus, the area on the upper right corner of the graph shows potential storage for the CCSU while the bottom right corner shows potential seal.

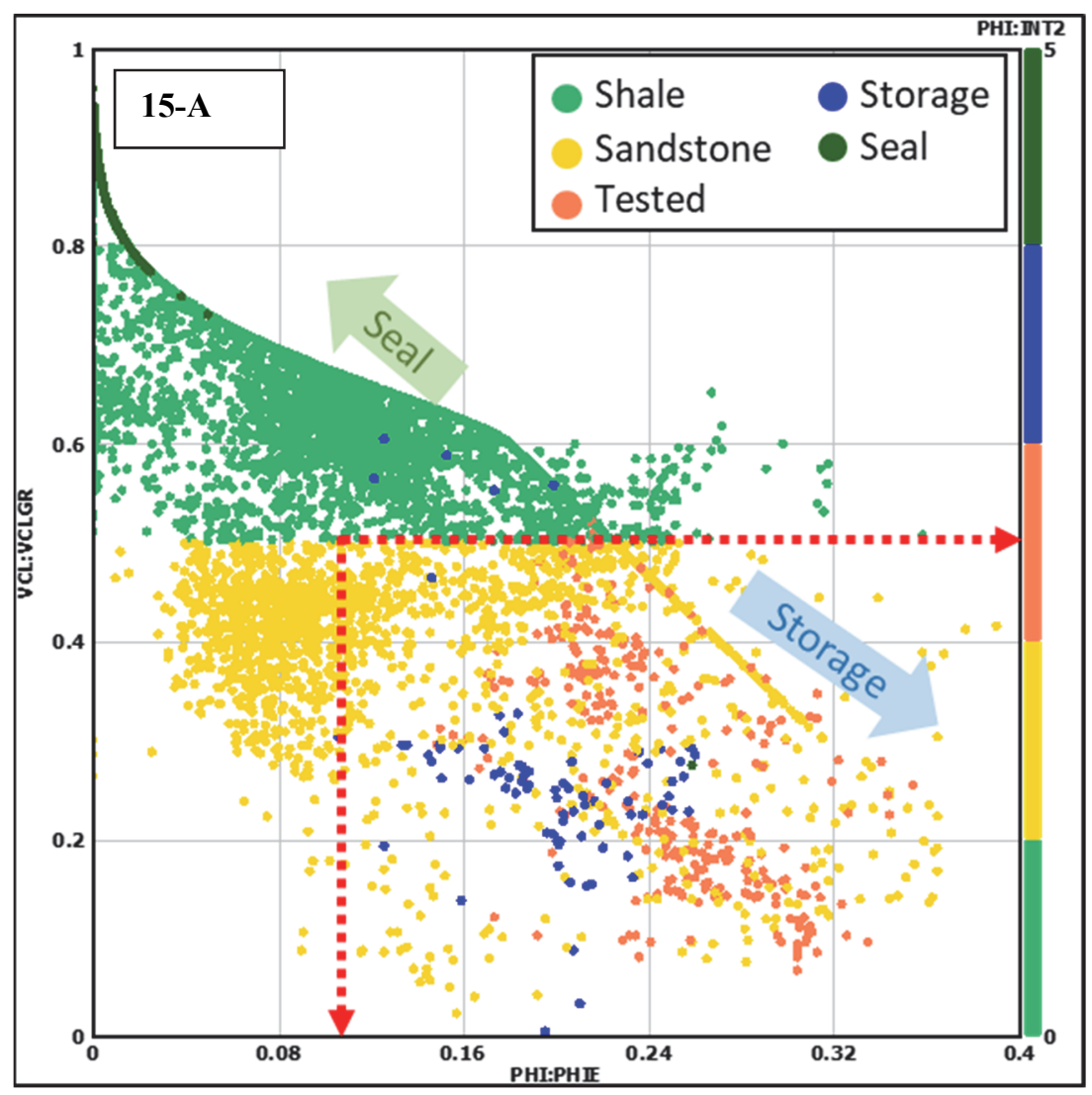




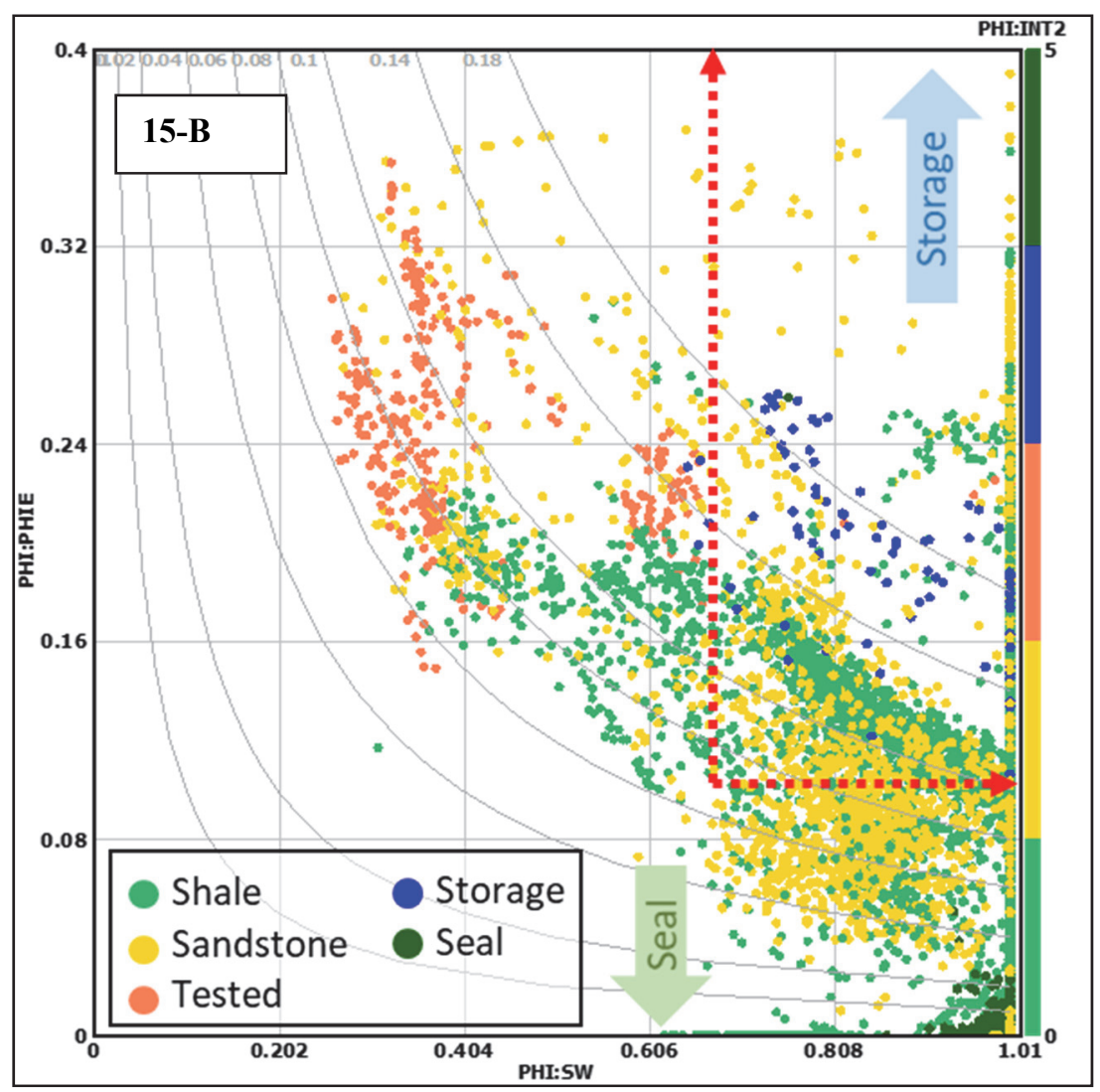

Figure 15. Storage and seal property cut-offs: Clay volume and effective porosity plot (Fig . 15-A) and water saturation and effective porosity plot (Fig. 15-B)

\subsection{CCSU Storage and Seal Delineation}

Based on the parameter cut - off, the storage interval was delineated. In addition to the petrophysics cut - off, temperature and formation pressure was also implemented to determine an interval that has sufficient condition to store heat and maintain the carbon dioxide in supercritical phase. The result is shown in Figure 16. The blue bar shows where the suitable reservoir while the green bar shows the available seal throughout the well interval. The reservoir intervals are intermittent between the depth of 6200 to $7700 \mathrm{ft}$. The most potential reservoir is determined to be EGS-2 that is located between 6816-6831 ft. The sandstone is also overlain by $15.17 \mathrm{ft}$ thick shale that would act as its primary seal. 


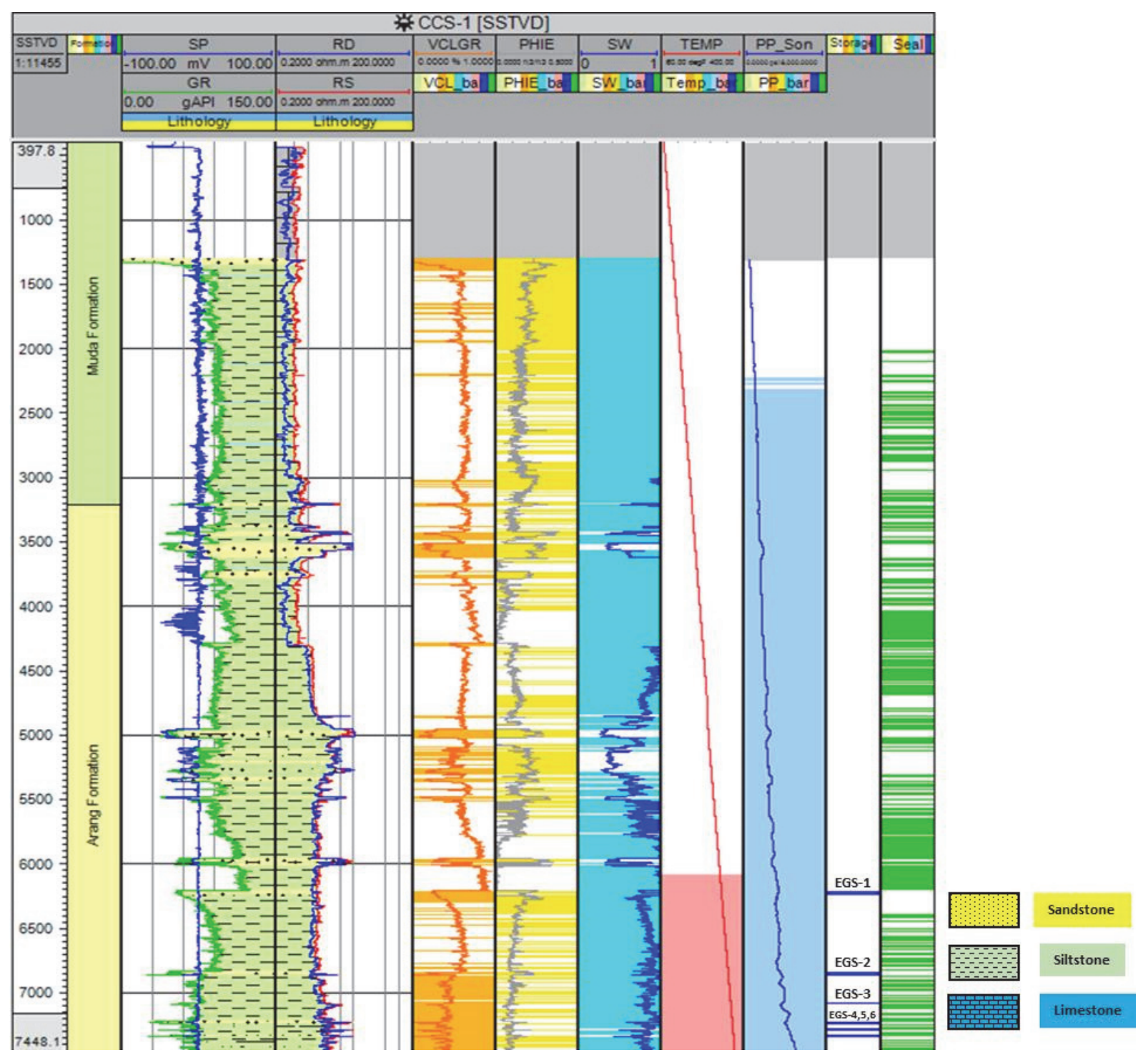

Figure 16. Reservoir and seal intervals delineation

The properties for EGS-2 zone both storage and seal is shown in Figure 17 and summarized in

Table 3. This interval is selected due to its lateral distribution. The result of the subsurface mapping (Figure 18 \& Figure 19) shows the injection point of CCS-1 well would be located at $6850 \mathrm{ft}$ that has an average pressure of $3543 \mathrm{psi}$ and temperature of $335^{\circ} \mathrm{F}$ while the top of the anticline is located at the depth of $\pm 6000 \mathrm{ft}$ which has an average pressure of $2647 \mathrm{psi}$ and a temperature of $300^{\circ} \mathrm{F}$. 


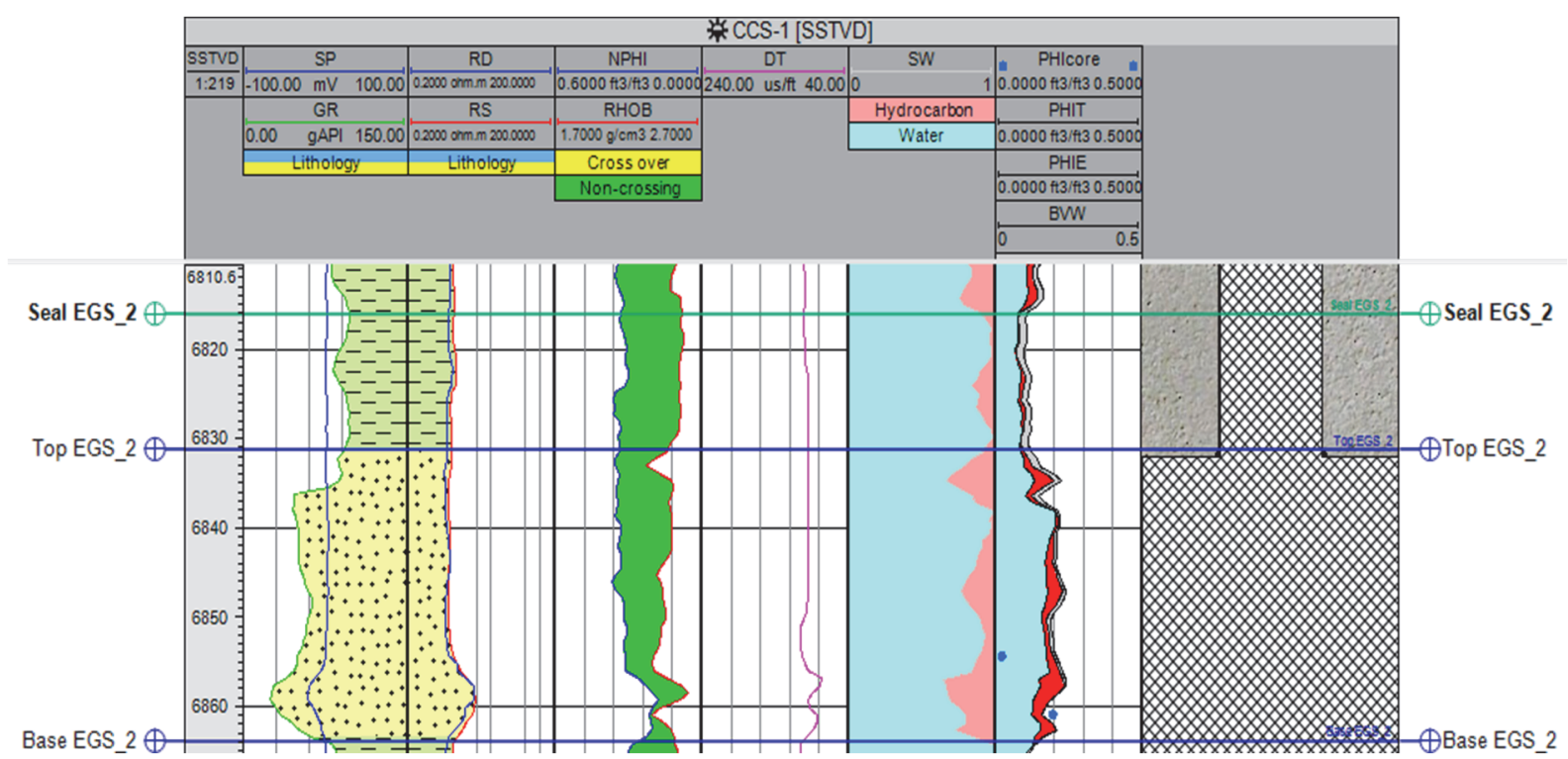

Figure 17. Proposed CCSU reservoir and seal section

Table 3. Summary of storage and seal properties

\begin{tabular}{lll}
\hline CCSU & Reservoir & Seal \\
\hline Lithology & Sandstone & Shale \\
Depth (ft) & $6831-6863$ & $6816-6831$ \\
Thickness (ft) & 32 & 15 \\
VClay & 0.261 & 0.606 \\
PHIE & 0.188 & 0.088 \\
PHIT & 0.199 & 0.112 \\
SW & 0.83 & 0.93 \\
Pressure (psi) & 3543 & 3365 \\
Temperature ( ${ }^{\circ}$ F) & 335 & 335 \\
\hline
\end{tabular}

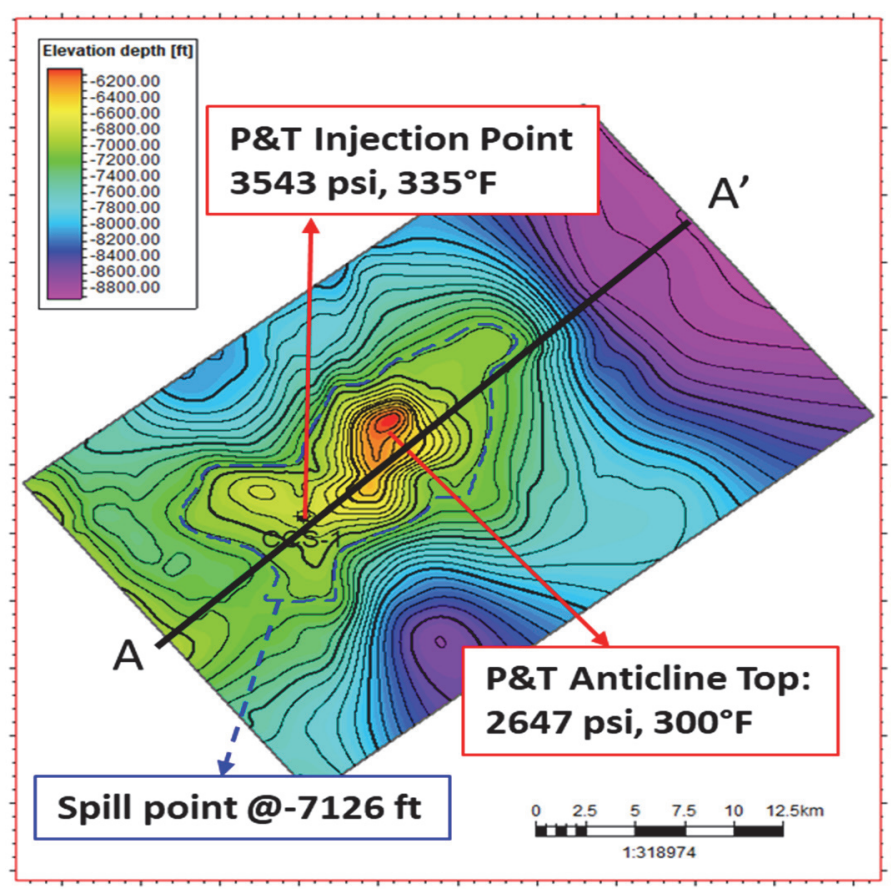

Figure 18. Depth Structure map of the EGS-2 top 


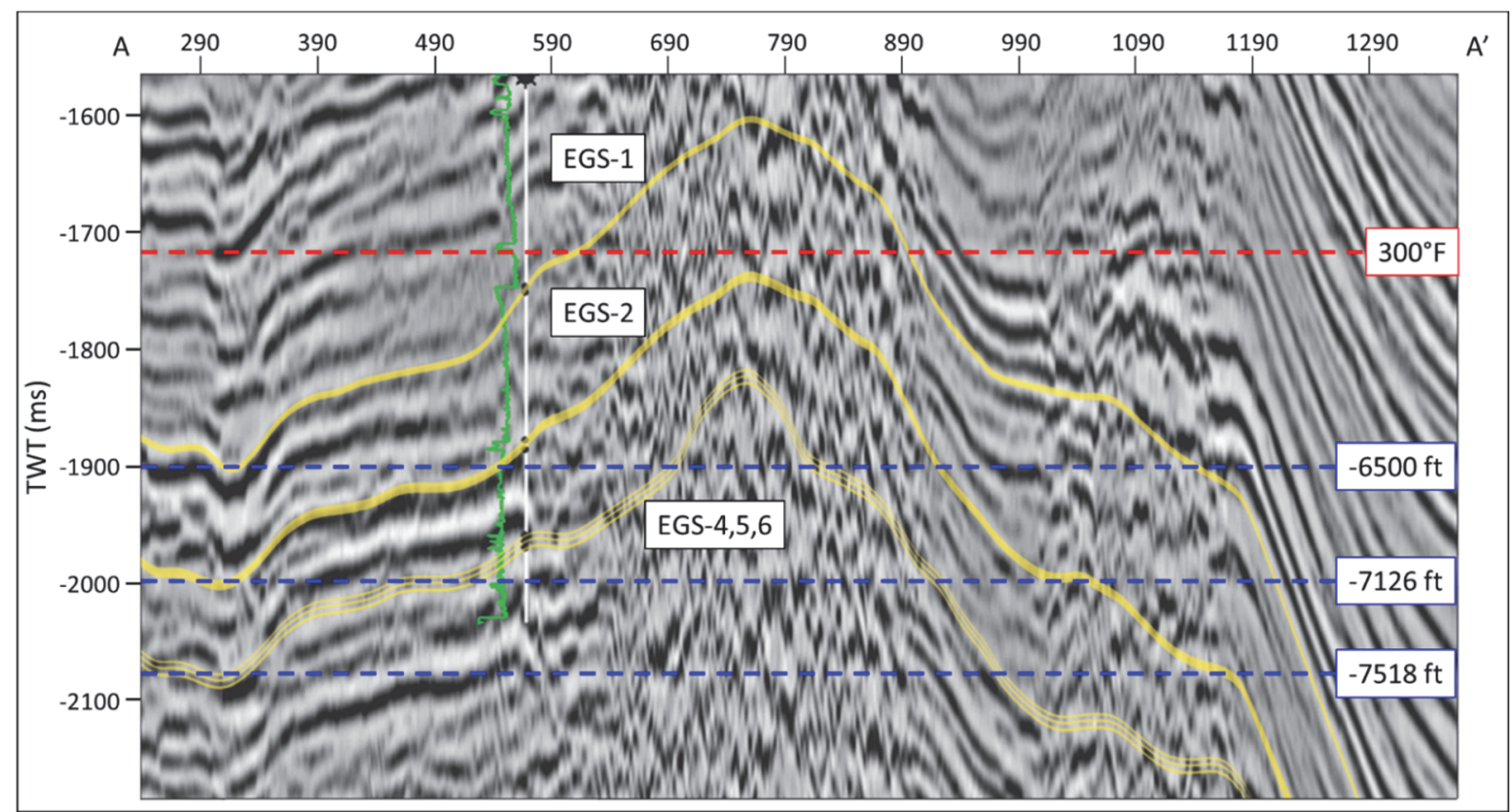

Figure 19. A - A' Seismic section of CCS-1 well

\subsection{Storage Capacity and Contingent Storage Resource Estimation}

Depth structure maps of the EGS-2 top and base has been mapped using the available seismic in the region. The structure has a closure at $7126 \mathrm{ft}$ (Figure 18). Injection from CCS - 1 well is planned at the depth of $\pm 6850 \mathrm{ft}$ that is equal to $3543 \mathrm{psi}$ and $335^{\circ} \mathrm{F}$ as mentioned earlier in the storage properties summary. The gas composition from the well test was calculated for its Formation Volume Factor $(\mathrm{Bg})$ and density $(\rho \mathrm{g})$ as shown in Figure 20.
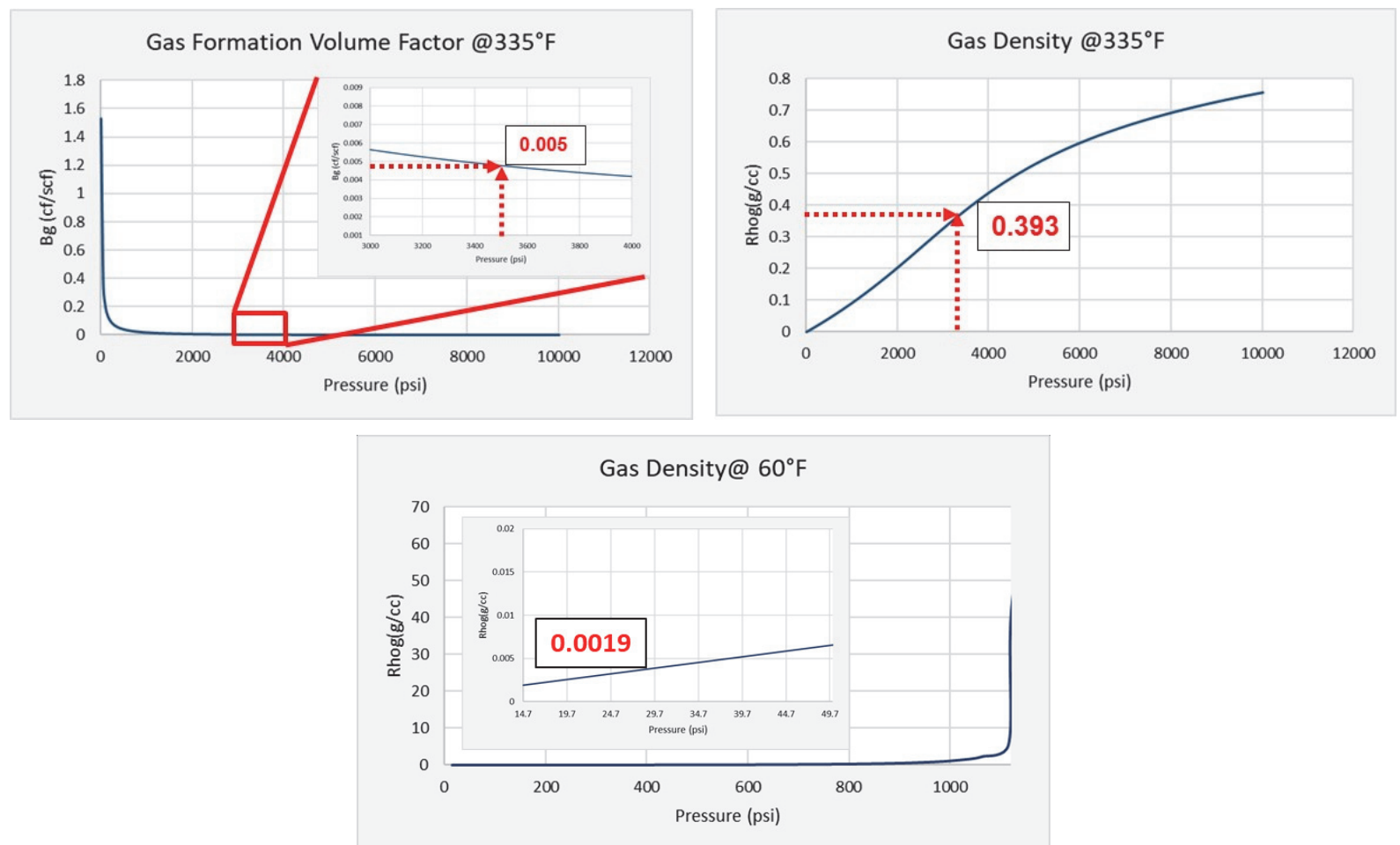

Figure 20. Fluid properties of $\mathrm{CO} 2$ at $335^{\circ} \mathrm{F}$ : formation volume factor (left) and density (right)

The parameters that were used to estimate the storage capacity is summarized in 
Table 4. The volumetric result of EGS-2 interval is shown in

Table 5 .

Table 4. Storage capacity estimation parameters of EGS-2 storage

\begin{tabular}{lll}
\hline Parameter & Value & Description \\
\hline Net to Gross & 1 & \\
Porosity & 0.188 & Average effective porosity \\
Gas Saturation & 0.74 & $1-\mathrm{Sw}$ \\
Volume factor (cf/scf) & 0.005 & $\mathrm{Bg} @ 3543 \mathrm{psi}$ \\
Gas density (g/cc) & 0.393 & Gas density @ 3543 psi and $335^{\circ} \mathrm{F}$ \\
& 0.00189 & Gas density @ 14.67 psi and $60^{\circ} \mathrm{F}(\mathrm{STP})$ \\
\hline
\end{tabular}

Table 5. Volumetric estimation result of EGS-2 storage capacity

\begin{tabular}{ll}
\hline Volumetric Result & Value \\
\hline Bulk Volume (BCF) & 44.21 \\
Pore Volume (BCF) & 8.31 \\
CO2 Pore Volume (BCF) & 6.15 \\
Storage Capacity (BSCF) & $1,308.63$ \\
Storage Capacity (MM Tonnes) & 70.29 \\
\hline
\end{tabular}

Potential reservoirs that lies above and beneath EGS-2 were also calculated for contingent storage resource. The parameters and result is shown in Table 6. In total, the structure has the potential to hold 1,559.49 Billion Standard cubic feet or 83.76 Mega tonnes of carbon dioxide.

Table 6. Contingency storage resource volumetric.

\begin{tabular}{|c|c|c|c|c|c|c|c|c|}
\hline \multirow{2}{*}{ Reservoir } & \multirow{2}{*}{$\begin{array}{l}\text { Bulk V } \\
\text { (BCF) }\end{array}$} & \multirow{2}{*}{ NTG } & \multirow{2}{*}{ Porosity } & \multirow{2}{*}{$\begin{array}{l}\text { Gas } \\
\text { Saturation }\end{array}$} & \multirow{2}{*}{ Bg (cf/scf) } & \multirow{2}{*}{$\begin{array}{l}\text { Gas Density } \\
@ 14.67 \text { PSI (g/cc) }\end{array}$} & \multicolumn{2}{|c|}{ Storage Capacity } \\
\hline & & & & & & & BSCF & MM Tonnes \\
\hline EGS-1 & 4.67 & 1 & 0.20 & 0.74 & 0.005 & 0.00189 & 146.23 & 7.85 \\
\hline EGS-4 & 2.24 & 1 & 0.13 & 0.74 & 0.005 & 0.00189 & 47.00 & 2.53 \\
\hline EGS-5 & 1.16 & 1 & 0.17 & 0.74 & 0.005 & 0.00189 & 31.04 & 1.67 \\
\hline EGS-6 & 1.16 & 1 & 0.15 & 0.74 & 0.005 & 0.00189 & 26.58 & 1.43 \\
\hline Total & & & & & & & 250.86 & 13.48 \\
\hline
\end{tabular}

\section{Conclusion and Recommendation}

The most suitable reservoir for the CCSU operation is located at the depth of $6831-6863 \mathrm{ft}$. The lithology iss siliclastic sandstone with a thickness of $32 \mathrm{ft}$. The average reservoir is estimated to be consisted of 0.26 clay and 0.83 water saturation with 0.207 total porosity and 0.197 effective porosity. It holds an average pressure of 3542 psi and $335^{\circ} \mathrm{F}$.

The accompanying seal is located at the depth of $6816-6831 \mathrm{ft}$. The lithology is shale with a thickness of $15 \mathrm{ft}$. The average reservoir is estimated to be consisted of 0.61 clay and 0.925 water saturation with 0.088 total porosity and 0.0068 effective porosity. It holds an average pressure of $2687.55 \mathrm{psi}$ and $335^{\circ} \mathrm{F}$.

The storage capacity for carbon dioxide in the EGS-2 interval is 1308.63 billion standard cubic feet or 70.29 mega tonnes.

The contingent storage resource for the structure is 250.86 billion standard cubic feet or 13.48 mega tonnes.

In total, the structure has the potential to store $1,559.49$ billion standard cubic feet or 83.76 mega tons of carbon dioxide

\section{Acknowledgement}

The authors wish to thank Institut Teknologi Bandung for providing support to work on this research and Ditjen MIGAS for their permission to publish this paper. 


\section{Glossary}

\begin{tabular}{|c|c|c|}
\hline$V_{\text {Clav }}$ & : & Clay volume or content $(\mathrm{v} / \mathrm{v})$ \\
\hline$G R_{\text {loa }}$ & : & Measured gamma ray (API) \\
\hline$G R_{\min }$ & : & Minimum gamma ray from clean sand interval (API) \\
\hline$G R_{\max }$ & : & Maximum gamma ray from claystone interval (API) \\
\hline$\phi_{D}$ & : & Density porosity (v/v) \\
\hline$\rho_{m a}$ & : & Matrix density (g/cc) \\
\hline$\rho_{b}$ & : & Bulk density (g/cc) \\
\hline$\rho_{f l}$ & : & Fluid density (g/cc) \\
\hline$\phi_{N}$ & : & Neutron porosity $(\mathrm{v} / \mathrm{v})$ \\
\hline$\phi_{\text {total }}$ & : & Total porosity (v/v) \\
\hline$\phi_{\text {eff }}$ & : & Effective porosity $(\mathrm{v} / \mathrm{v})$ \\
\hline$S_{w b}$ & : & Clay bound water $(\mathrm{v} / \mathrm{v})$ \\
\hline$S_{w}$ & : & Water saturation $(\mathrm{v} / \mathrm{v})$ \\
\hline$R_{s h}$ & : & Shale resistivity (Ohm.m) \\
\hline$R_{w}$ & : & Water resistivity (Ohm.m) \\
\hline$R_{t}$ & : & Deep resistivity (Ohm.m) \\
\hline $\mathrm{a}$ & : & Tortuosity factor \\
\hline $\mathrm{m}$ & : & Cementation exponent \\
\hline $\mathrm{n}$ & : & Saturation exponent \\
\hline$\sigma$ & : & Overburden stress (PSI) \\
\hline$\sigma^{\prime}$ & : & Effective stress (PSI) \\
\hline$P_{p}$ & : & Pore pressure (PSI) \\
\hline$P_{h v d}$ & : & Hydrostatic pressure (PSI) \\
\hline$\Delta T_{n}$ & : & Sonic log's normal compaction trend \\
\hline$\Delta T_{\text {loa }}$ & : & Measured sonic $\log (\mu \mathrm{sec} / \mathrm{ft})$ \\
\hline $\mathrm{BSCF}$ & : & Billion Standard Cubic Feet (10^9 Cubic Feet) \\
\hline MM Tonnes & : & Million Tonnes ( $10^{\wedge} 6$ Tonnes $)$ \\
\hline
\end{tabular}

\section{References}

Amaefule, J. O., Altunaby, M., Tiab, D., Kersey, D. G., \& Keelan, D. K. (1993). Enhanced Reservoir Description: Using Core Log and Log Data to Identify Hydraulic Flow Units and Predict Permeability in Uncored Intervals/Wells. Paper SPE 26436.

Bachu, S. (2015). Review of CO2 storage efficiency in deep saline aquifers. International Journal of Greenhouse Gas Control, 188-202.

Baker, R., Yarranton, H., \& Jensen, J. (2015). Practical Reservoir Engineering and Characterization. Waltham, Massachusetts, USA: Elsevier.

Benzagouta, M. S. (2013). The use of polar angle, polar arm and other physical attributes in rock characterization. Journal of King Saud University - Engineering Sciences.

Buryakovsky, L., Chilingar, G., Rieke, H., \& Shin, S. (2012). Fundamentals of the Petrophysics of Oil and Gas Reservoirs. Beverly: Scrivener Publishing.

Darman, H. (2017). Seismic Expression of Key Geological Features in The East Natuna Basin. Buletin Forum Sedimontologi Indonesia Number, 38, 54. Jakarta: FOSI.

Dunn, P. A., Kozar, M. G., \& Budiyono, (1996). Application of Geoscience Technology in a Geologic Study of 
the Natuna Gas Field, Natuna Sea, Offshore Indonesia, IPA Proceedings IPA96-1.0-164.

GRC. (2017, 12 25). What is Geothermal? Retrieved from Geothermal Research Council. Retrieved from https://geothermal.org/what.html

Holstein, E. (2007). Petroleum Engineering Handbook Volume V: Reservoir Engineering and Petrophysics. Richardson: Society of Petroleum Engineers.

Mouchet, J. P., \& Mitchell, A. (1989). Abnormal Pressures While Drilling. Boussens: Elf Aquitane.

Pruess, K., \& Spycher, N. (2010). Enhanced Geothermal Systems (EGS) with CO2 as Heat Transmission Fluid A Scheme for Combining Recovery of Renewable Energy with Geologic Storage of CO2. World Geothermal Congress 2010. Bali Indonesia.

Raharja, M., Carmody, S., Cherdasa, J., \& Haribowo, N. (2013). Dual Paleogene and Neogene Petroleum Systems in East Natuna Basin: Identification of A New Exploration Play in the South Sokang Area. 37th IPA Annual Convention and Exhibition Proceedings. Jakarta: Indonesian Petroleum Association.

Sugihardjo, Aprillian, S. S., Yusuf, A., \& Sumardan, S. (1999. Investigations of the Storage Efficiency of CO2 in Carbonate Aquifers, IPA Proceedings IPA99-E-029.

Zoback, M. D. (2007). Reservoir Geomechanics. New York: Cambridge University Press.

\section{Copyrights}

Copyright for this article is retained by the author(s), with first publication rights granted to the journal.

This is an open-access article distributed under the terms and conditions of the Creative Commons Attribution license (http://creativecommons.org/licenses/by/4.0/). 